\title{
Pensamiento pop en Black Mirror. El monstruo y su linchamiento
}

\section{Pop Thinking in Black Mirror. The monster and his lynching}

\author{
Jorge Martínez Lucena. Universitat Abat Oliba CEU
}

Javier Cigüela Sola. Universität Freiburg de Alemania

Recibido: 20-II-2014 - Aceptado: 30-V-2014

Resumen:

El artículo trata de explorar la manifestación en la teleserie Black Mirror de lo que denominamos pensamiento pop: un tipo de narrativa del entretenimiento que puede funcionar también como herramienta de reflexión crítica sobre el mundo presente. Partiendo de la base de que la sociedad proporciona imaginarios sociales para facilitar la orientación individual, se analiza críticamente el imaginario del castigo manifestado en la serie. Ello se realiza conectando los fines del castigo en la teoría penal (prevención, retribución y resocialización) con las dos principales imágenes que se desprenden del capítulo 2.2.: la del monstruo y la del linchamiento. El producto de entretenimiento se transforma, contra lo que piensan sus críticos, en una herramienta de reflexión crítica.

Palabras clave:

Imaginarios sociales, monstruo, Black Mirror, meta-ficción, linchamiento.

Abstract:

The article explores how the TV series Black Mirror is a proof of what we call pop thinking: a type of entertaining narrative that can work as a tool for critical thinking of our present world as well.Taking into account how society provides social imaginaries to marshal our individual orientation, we explore the imaginary of punishment in this TV series. The article connects the aims of punishment according to criminal theory (prevention, retribution and rehabilitation) with two images that appears in episode 2.2: the monster and the lynching. The entertaining product transforms itself, against what its critics think, in a tool for critical thinking.

Key words:

Social imaginaries, monster, Black Mirror, meta-fiction, lynching. 


\section{Introducción}

La crítica de la televisión se ha mostrado generosa en las últimas décadas en campos como la sociología o la comunicología (Baudrillard, 1978; Bourdieu, 1997; Debord, 2000; Postman, 2012; Sartori, 1998). Conceptos como espectáculo, entretenimiento o simulacro han sido los caballos de batalla de este vector apocalíptico de nuestros estudios de los medios, iniciado en nuestra modernidad tardía por la escuela de Toronto y cuyo máximo epígono fue Marshall McLuhan (2009).

Sin embargo, parece que la idea de que el medio es el mensaje no limita sus efectos críticos a las primeras tecnologías de la pantalla, sino que cobra poder con la aparición de internet, las tablets, los smartphones o las redes sociales. Estas herramientas ganan cada vez mayor protagonismo en nuestras vidas concretas, tanto en el ámbito público-laboral como en el privado.

Algunos tecnólogos actuales parecen confirmar, desde estudios psicológicos y neurológicos (Carr, 2013), las profecías más pesimistas sobre el futuro de la cultura que se hicieron hace ya dos décadas (Postman, 1994). Otros consideran, en cambio, que el efecto nocivo de las tecnologías es simplemente la consecuencia de un cambio de paradigma (Thompson, 2012), o que puede compensarse con el conocimiento crítico de los medios o tecnologías en cuestión y con la educación que tiene en cuenta y contrarresta sus posibles efectos nocivos (Rheingold, 2012).

Nuestra contribución pretende argumentar mínimamente en contra de las posiciones más apocalípticas con respecto a las nuevas tecnologías. Queremos evidenciar, de la mano de la miniserie británica Black Mirror (Charlie Brooker, 2011), y más en concreto del estudio del capítulo "White Bear" (2.2) de tal teleserie, que las nuevas tecnologías pueden resultar una estimable fuente de conocimiento crítico acerca de las nuevas tecnologías. Paradójicamente, tal conocimiento crítico se hace posible precisamente a través de la experiencia del visionado de un producto cultural entretenido. Es decir, contra el parecer de los más pesimistas, el mero espectáculo puede ser criticado a través del propio espectáculo, generando lo que en este artículo denominaremos pensamiento pop.

La metodología que vamos a seguir en este artículo va a consistir en el estudio teórico y en el comentario hermenéutico del mencionado texto audiovisual, fundamentalmente a la luz de dos bibliografías. Por un lado, la correspondiente a la teoría sociológica de los imaginarios sociales y su aplicación al mundo de la comunicación audiovisual. Por el otro, la correspondiente a la teoría del castigo, a caballo entre la sociología y la teoría del derecho penal.

El recorrido de la argumentación será el siguiente. En primer lugar, haremos una breve explicación de las características estilísticas y de los contenidos de la mencionada miniserie de Channel 4. En segundo lugar, introduciremos algunos conceptos de la teoría de los imaginarios sociales y los aplicaremos al capítulo 2.2, mostrando la condición de micro-mito de la teleserie Black Mirrory su capacidad para transmitir determinados imaginarios sociales mediante imágenes como la del 
monstruo y su linchamiento. En tercer lugar, ya establecido el objeto teórico de estudio, mostraremos cómo se hace efectiva la crítica a la sociedad tecnológica en el mencionado episodio de la serie, a través del recurso a las dos imágenes mencionadas y a la metaficción, y teniendo en cuenta la bibliografía teórica sobre el castigo. Para finalizar, intentaremos deducir de todo lo dicho la eventual viabilidad de lo que hemos llamado pensamiento pop.

\section{El narcisismo televisivo en Black Mirror: el espejo negro se rompe}

En una sociedad avanzada como la nuestra, resultado de una severa racionalización, se requieren más que nunca mecanismos de reencantamiento del mundo y de la realidad para responder a las expectativas de los individuos (Ritzer, 2000). El resultado es que "nuestra civilización racionalista y su culto por la desmitificación objetiva se ven sumergidos de hecho por la resaca de la subjetividad maltratada y lo irracional” (Durand, 2004: 432-433).

Por otro lado, el poder de los mitos se ve reforzado por la caída de grandes metarrelatos (Lyotard, 1987), antaño capaces de dar unidad y cohesión a las experiencias tanto individuales como colectivas, que ahora quedan entregadas a la anomia, a una ausencia de norma, dirección y sentido, que requiere de otros métodos de articulación. Como leemos: "La cultura de masas es la encargada de abastecer a lo cotidiano de imágenes y modelos míticos de un mundo ficcional que da forma a las aspiraciones, sueños y anhelos tanto individuales como colectivos. Lo imaginario, de este modo, contribuye a configurar lo real" (Carretero, 2006: 122).

\subsection{La nueva era de la serialidad televisiva}

Desde su nacimiento, tanto el cine como la televisión han jugado un papel muy importante en la configuración de la estabilidad psicológica y social de las sociedades contemporáneas. A caballo entre ambos tenemos la serialidad televisiva, que en la actualidad está viviendo lo que se ha denominado la tercera edad de oro de la televisión (Pérez, 2011), por la altísima calidad de tales productos audiovisuales, cuya última oleada se iniciaría con la irrupción en la HBO (Cascajosa Virino, 2006) de Los Soprano (1999-2007) (Sepinwall, 2012).

Estos excelentes estándares de la serialidad televisiva actual no son la única razón de su gran poder configurador. Mientras que una película supone una exposición media del espectador al producto audiovisual de un par de horas, la experiencia del espectador de una teleserie supone muchísimo más tiempo de visionado. A ello se le suman las múltiples posibilidades de ampliar la superficie de contacto con el mundo ficticio de la teleserie a través de la transmedialidad (Bellón, 2012), rastreable en páginas web, redes sociales, webisodios, spin-offs, etc.

Desde la doble herencia cinematográfica y televisiva, la nueva serialidad televisiva es deudora de cambios que se han producido tanto en el cine posmoderno como en la misma televisión. El cine ha ganado en complejidad (Boggs y Po- 
llard, 2001), se ha hecho neo-barroco en cuanto a la estética (Calabrese, 1989). Una de sus nuevas constantes es la autorreferencialidad metadiscursiva de la imagen-distancia, que implica una actitud cognitiva del espectador ante la multitud de "guiños, citas, alusiones, referencias". Estas películas se complacen en acentuar "la distancia con respecto de ellas mismas, induciendo al espectador a adoptar una distancia parecida respecto de lo que ve” (Lipovetsky y Serroy, 1009: 124).

En cuanto a la televisión, también parece haber sufrido cierta mutación. Tras la paleotelevisión y la neotelevisión, llega la metatelevisión, que también supone una cierta capacidad de lectura y actitud lúdica del espectador frente al texto, además de autorreferencialidad (Olson, 1987). La metatelevisión "se caracteriza por hablar incesantemente de ella misma" (Tous, 2009: 177), "juega con su propia representación y, mediante la deformación (lo grotesco), la parodia (la duplicación de la realidad), la reflexividad (los programas de zapping), la televisión se mira a sí misma, se contempla en su propio espejo, pero en un espejo deformado, que cae con facilidad en lo grotesco" (Imbert, 2008:16).

\subsection{El papel de la metaficción en la ficción televisiva actual}

Dentro de este contexto, resulta lógico que la serialidad televisiva actual tenga como uno de sus recursos o fenómenos favoritos el de la metaficción (García Martínez, 2009). Ésta no es otra cosa que la ficción autoconsciente, esto es, que se sabe ficción, y que se contempla a sí misma en su condición de artefacto. Ello permite que el lector o el espectador caiga en la cuenta y reflexione sobre las eventuales relaciones entre aquella ficción y la realidad (Waugh, 1984: 2). Son ejemplo reciente de esto tanto la continua rotura de la cuarta pared de Francis Underwood en House of Cards (2013-), como Jorge Sanz interpretándose a sí mismo en la mini-serie de Canal+ ¿Qué fue de Jorge Sanz? (2010), el cómic de la mini-serie británica Utopía (2013) que resulta premonitorio con respecto a la trama del relato o la mirada sobre las tripas de la televisión en la que Aaron Sorkin reincide con TheNewsroom (2012-).

Los tipos de metaficción son muy diversos, pero la que fundamentalmente nos preocupa en este artículo es el llamado "narcisismo televisivo" (García Martínez, 2009: 657), que no es más que el mencionado intento de retratar lo que sucede tras la pantalla "como pretexto para el homenaje (...) o, con mayor frecuencia, para la autocrítica" (Pérez Bowie, 2005: 123). Se trata de un recurso bastante común en el campo de la serialidad televisiva, con ejemplos conocidos como Entourage (20042011), Extras (2005-2007), Studio 60 (2006), 30 Rock (2006-2013).

Uno de los creadores que más ha practicado este narcisismo televisivo en la realización de teleseries es Charlie Brooker, no sólo en miniseries como Black Mirror (2011-) o Dead Set (2008), sino también en la teleserie documental How TV Ruined your life (2011-). En Dead Set aborda el género zombi. Los únicos supervivientes de la plaga londinense son los que están encerrados en el plató de Gran Hermano. La trama consiste en la progresiva conversión de todos los supervivientes, que provoca en el espectador la creciente sensación de que se nos está hablando de los realityy de sus efectos. En How TV 
ruined your life, el mismo Charlie Brooker, adoptando la narrativa documental de la BBC, se inviste con la aureola y la credibilidad del periodista para mostrar los efectos de la TV en nuestras vidas.

\subsection{El espejo negro se rompe}

Pero quizás donde el narcisismo televisivo de Charlie Brooker llega a su ápice es en Black Mirror. Esta miniserie británica de tres capítulos por temporada, que va ya a por su tercera, es un retablo visual en el que su serialidad no se encuentra en la unidad narrativa de la trama de los diferentes episodios sino en el tema sobre el que cada uno de estos trata. En ella se retrata la pantalla (blackmirror) o pantallas de las nuevas tecnologías que han invadido nuestra cotidianidad modificándonos, transformándonos, cambiándonos, planteándonos nuevos problemas que auguran, según parece advertir Brooker, negros (black) horizontes. Él mismo afirma: "en estos momentos somos todos como niños en un planeta en el que todos los adultos se han marchado y nos han dejado sin supervisión. Los avances se nos presentan siempre como algo sólo positivo, pero no percibimos las cosas que vamos perdiendo ni el efecto que tiene en nuestras mentes" (Gómez Urzáiz, 2013).

En los diferentes capítulos de esta teleserie se van explorando, mediante la unión entre el recurso al narcisismo televisivo con tramas inteligentes, ámbitos en los que la relación entre tecnología y usuario se ha vuelto especialmente problemática.

Así lo hace, por ejemplo, respecto al ámbito político: tanto en “The National Anthem” como en "The Waldo Moment” se nos muestra un sistema político dominado por la tensión entre opinión pública y tecnología. Al mostrar la influencia social de fenómenos como Youtube, las redes sociales, los diferentes media y la "pulsión escópica" del tele-espectador, la serie llama a reflexionar sobre temas como la relación entre democracia y tecnología, o entre poder y manipulación.

En otros capítulos - “The Entire History of You” o "Be Right Back”- se muestra de qué modo la tecnología afecta a la experiencia humana de la relación amorosa, cada vez más mediada por internet y las redes sociales. En ellos se trata la relación existente entre memoria y perdón, y entre la realidad y su reencantamiento a través lo que se ha llamado las catedrales del consumo (Ritzer, 2000).

En “White bear", cuyo desarrollo se explicará detalladamente en 4.3, se explora la relación entre justicia y tecnología. Mediante una trama en la que una joven despierta en un mundo lleno de gente alienada en su móvil, y donde se ve abocada a huir de un grupo de psicópatas que persiguen a los pocos sujetos libres, se invita al espectador a reflexionar acerca de fenómenos como los juicios mediáticos o los linchamientos públicos tecnológicos.

Con estos ejemplos de rendimiento del narcisismo televisivo en favor de la crítica de las nuevas tecnologías, se entiende mejor la titlesequence de esta miniserie británica. En ella aparece primero el título “BLACK MIRROR” impresionado sobre un fondo negro, y un segundo después ese fondo se agrieta violentamente, como la pantalla de un smartphone que hubiese 
estallado al ser golpeada. Vemos así sintéticamente que la metaficción, de la que el narcisismo televisivo no es más que un tipo, es un "espejo roto" (García Martínez, 2009). Ella hace añicos la ilusión, porque rompe el ensimismamiento alienado en la alteridad del mundo ficticio. Con ello devuelve al espectador a la conciencia sobre el mundo real y le otorga poder a la eventual verdad metafórica de la narración de ficción.

\section{Los imaginarios sociales en "White Bear"}

La nueva configuración de nuestras sociedades posmodernas, deudora en gran medida de la ya mencionada caída de los metarrelatos, ha generado la necesidad teórica de explicar la cohesión social de un modo que sea compatible con un contexto democrático y con la incontestable anomia generalizada del individuo posmoderno. Éste habría atravesado mientras tanto "una revolución subjetivista, no sometida a sacrificios individuales sino a gratificaciones inmediatas, sin necesidad de coherencia ideológica y sin aspiraciones a grandes transformaciones históricas" (Barraycoa, 2003: 96). Uno de los intentos de respuesta a esta pregunta teórica ha sido la teoría de los imaginarios sociales (Castoriadis, 1987; Maffesoli, 2003 y 2004; Appadurai, 2001; Taylor, 2006a y 2006b; Imbert, 2010).

\subsection{Imaginario social y micromito}

Los imaginarios sociales son aquellas imágenes o grupos de imágenes compartidos socialmente de un modo más o menos inconsciente, que permiten a los individuos de una determinada sociedad distinguir lo que es normal de lo que es anormal y lo que es real de lo que no lo es. El filósofo canadiense Charles Taylor los define como el modo en que las personas "imaginan su existencia social, el tipo de relaciones que mantienen unas con otras, el tipo de cosas que ocurren entre ellas, las expectativas que se cumplen habitualmente y las imágenes e ideas normativas más profundas que subyacen a estas expectativas" (2006a: 37).

Así, los imaginarios nos permiten habitar inadvertidos mapas de conducta que estabilizan la psicología individual, dándole unos ejes de coordenadas para buscar el sentido de la propia existencia, y que actúan como cemento social en ausencia de metarrelato.

Según la mencionada teoría de los imaginarios, estos llegan a nosotros a través de los mitos. El mito es, así: "la lógica que actúa para dar al mundo una unidad, un orden, un sentido primordial; es captar cómo la creación pensada a partir de un caos inicial impone sin cesar el doble juego de las fuerzas del orden y el desorden, y las figuras mediante las cuales ellas actúan" (Balandier, 1996: 19).

Pero los mitos actuales son micromitos. Han abandonado su pretensión omni-comprensiva y omni-explicativa, para centrarse mucho más en el reencantamiento del presente a través de la experiencia de la intensidad. Ya no se trata demitos 
fundadores capaces de dar respuesta a las grandes preguntas del hombre en función de un futuro más o menos utópico. Se trata, en cambio, de mitos fundamentales e indubitables que garantizan la estabilidad del sistema -léase, por ejemplo, la confianza que tenemos en la esfera pública, la relación ciudadano-estado y el mercado (Taylor, 2006b)-. Estos mitos se enriquecen y sepultan bajo una hipertrófica multiplicidad de ofertas simbólicas que permiten, en su elección y consumo, la construcción de la identidad de los individuos a través de pertenencias débiles a lo que se ha dado en llamar neo-tribus posmodernas (Maffesoli, 2004).

Igual que la modernidad supuso la substitución de lo religioso por lo político (Barraycoa, 2003), en la posmodernidad "lo mediático ha suplantado a lo político" (Balandier, 1994: 68). O, dicho de otro modo: "hoy la ideología ha sido suplantada por los imaginarios, desalojada por el espectáculo..." (Imbert, 2008: 30). El modo de dirigirse el poder ha virado completamente. Ha dejado de ser represor y ha pasado a la seducción como la mejor de sus estrategias. La imagen deviene una gran fuerza generadora de micromitologías que favorecen el despliegue de lo imaginario. Así, se produce finalmente "una indiferenciación entre lo imaginario y lo real, puesto que ambos, en perfecta amalgama simbiótica, conformarían aquello admitido como realidad para las sociedades en las que prima la cultura mediática" (Carretero, 2003: 95).

Con ello, micromitos como Justin Bieber, Cristiano Ronaldo, el Barça, los Angeles Lakers, Los New York Nets, Adele, David Foster Wallace, El Señor de los Anillos, Gran Hermano, Breaking Bad o Friends, se convierten en el vehículo a través del cual recibimos e intercambiamos los imaginarios. Y, como dice Carretero: “Un doble mecanismo antropológico de proyección e identificación es lo que va a permitir la ósmosis entre lo cotidiano y el campo imaginario”(2006: 122).

\subsection{La función estabilizadora del imaginario: el monstruo y su linchamiento}

La función fundamental de los imaginarios es la que los mitos han acreditado a lo largo y ancho de la historia de la humanidad. Como la imaginación humana, el mito siempre ha tenido una función estabilizadora (Carretero, 2006: 122), que consiste en ayudarnos a ver el mundo de un modo en que predomine el orden sobre el caos. Se trata de algo profundamente arraigado, porque "las personas corrientes «imaginan» su entorno social (...) a través de imágenes, historias y leyendas" (Taylor, 2006a: 37). Por eso mismo: "El mito [la imagen], sin embargo, procura distanciar al hombre de esta primigenia 'angustia vital', consiguiendo racionalizar la inseguridad para transformarla en algo que se torna accesible y, de este modo, reconduce lo inhóspito a una imagen familiar" (Carretero, 2006: 108).

Tal función estabilizadora también cuenta con una vertiente social que se hace evidente en la siguiente definición de imaginario social: "Es la concepción colectiva que hace posibles las prácticas comunes y un sentimiento ampliamente compartido de legitimidad” (Taylor, 2006a: 37). Se convierten, por tanto, en un inadvertido criterio de normalidad y anormalidad, siguiendo la terminología de Foucault (2001), que prevalece en nuestras sociedades. 
Una de las imágenes más utilizadas en los mitos para identificar la anormalidad es el monstruo, que permite señalarla y protegerse de ella en dos niveles: uno psicológico, en que el individuo es alejado de su propia inclinación hacia tal desviación de la conducta; y otro social, en que la sociedad se blinda ante la posible desestabilización y la eventual irrupción de la revolución. El monstruo es el que se escapa de lo normal, el que proporciona a la sociedad la oportunidad de reafirmarse en su "normalidad", en sus valores compartidos. El monstruo proporciona el "cuerpo o alma sacrificados" a costa del cual se restablece el sentido y el orden social (Foucault, 1979: 19ss).

Dicho sacrificio toma muy a menudo la forma de otra imagen mítica: el linchamiento. Éste supone un tipo de castigo, identificado con prácticas tribales de justicia, que ejecuta la sociedad misma, su población, y no una instancia judicial especializada. Con ese castigo público la sociedad escenifica la distancia con el "anormal", comunicando que el monstruo es diferente del "nosotros", y que su comportamiento obedece a una anormalidad de la que nadie más es corresponsable: ni la sociedad misma, ni el resto de los ciudadanos.

\section{La crítica a los imaginarios tecnológicos del castigo}

La post-modernidad, de la mano de las tecnologías de la pantalla y de la comunicación, ha llevado consigo la transformación del imaginario social referido al castigo, a la "pena" que se impone a un delincuente. La primera manifestación de dicha transformación, ampliamente desarrollada en torno a la teoría de sistemas, es la progresiva separación entre la "realidad" del castigo -un sujeto que entra en prisión, como paradigma- y la "comunicación" del castigo -esto es: sus consecuencias comunicativas, su impacto en el imaginario social- (Jakobs: 2006). Las más recientes evoluciones de la ciencia penal apuntan un giro hacia lo segundo, es decir: hacia un derecho penal que pasa a ser interpretado como "comunicación y nada más que comunicación" (Teubner, 2002: 551). En él se entiende el delito como comunicación de infidelidad a la norma y el castigo como comunicación de la vigencia del orden social más allá del delito.

Dicha substitución de "lo real por la comunicación de lo real” (Schünemann, 2003: 540s) tiene, no obstante, un correlato muy claro en la vida social contemporánea, y concretamente en la situación del delincuente. Si bien el castigo tiene la misma fisonomía de siempre (un sujeto que entra en prisión o recibe una multa), tecnologías como internet o la televisión lo han dotado de una significación social nueva, han multiplicado sus efectos. Para constatarlo basta estar atento a cualquier proceso penal actual: lo que no hace mucho se reducía a una patrulla policial que se presentaba discretamente en un domicilio, detenía a un presunto delincuente y lo llevaba a juicio para que se dictase sentencia, ahora puede adoptar la forma de un evento comunicativo de proporciones inmensas.

El mejor y más reciente ejemplo lo constituye el caso del “terrorista de Boston”. Lo excepcional no fue tanto su delito sino el tratamiento mediático que recibió, su transformación inmediata en reality. Su persecución y posterior captura fue seguida en directo por medio mundo a través de la televisión e internet, en programas regidos por un ejército de trabajadores 
de la comunicación (cámaras, reporteros, tertulianos, ciudadanos-espectadores, etc.) que amplificaron durante varios días los efectos comunicativos del proceso mismo. Se difundió repetidamente su contenido (la cara del delincuente, de las víctimas, sus intimidades, las conjeturas, sus historias familiares, etc.), teniendo con ello un efecto crucial e insospechado en la percepción social del delito.

La cara del delincuente se convirtió, poco después, nada menos que en portada de "Rolling Stone" (Agosto, 2013), con el siguiente titular: “"Thebomber”: cómo a un estudiante popular y prometedor le falló su familia, cayó en el islamismo radical y se convirtió en un monstruo". Sobre el transcurrir real del proceso, sin embargo, poco se sabe ya.

Toda esta transformación comunicativa se percibe con claridad, como se analizará a continuación en relación a los fines de la pena, tanto en "White Bear" como en determinados sucesos contemporáneos. El castigo penal está tomando cada vez más tintes de reality penitenciario, sucumbiendo a la necesidad postmoderna de comunicarlo todo, de convertirlo en espectáculo y entretenimiento. Todo lo cual, por cierto, funciona en el plano comunicativo a costa de la consideración de la "realidad" que supone el castigo: un sufrimiento muy significativo que se impone a un sujeto y que debe de estar legitimado y limitado a partes iguales.

\section{1. ¿Para qué castigar?}

Los efectos de las tecnologías de la comunicación en el imaginario social del castigo varían en función de qué finalidad se otorgue a la pena. Las razones por las que las sociedades han castigado delitos han sido integradas, con matices históricos y culturales, en torno a cuatro paradigmas.

1. La venganza, en la que el castigo ha de superar el mal que supuso el delito, y que corresponde a ideas de justicia primitivas.

2. La retribución, que busca la correspondencia entre el mal del delito y la pena que sufre el delincuente, en lo que supone un castigo "proporcional" a su culpabilidad y merecimiento (Kant, 2005: 166; Hegel, 2000: 192).

3. La prevención de futuros delitos, en tanto el castigo supone una amenaza para el resto de la población (Feuerbach, 1986: 43), al tiempo que reafirma la vigencia del orden jurídico (Jakobs, 1991: 5ss.), como también protege a la sociedad específicamente del delincuente, que mientras cumpla la pena no podrá delinquir. Este paradigma preventivo constituiría el "castigo útil”.

4. El último paradigma es la resocialización del delincuente en la sociedad, lo cual supondría una suerte de "castigo humanitario" y que, de hecho, es la única finalidad reconocida constitucionalmente en el Estado español (art. 25.2 CE). 
La corriente principal en la ciencia penal actual, con otros tantos matices, abogaría por una teoría de la unión, según la cual el castigo tendría como finalidad la prevención, siempre dentro del marco de la culpabilidad del sujeto (retribución), si bien en su momento "ejecutivo" ha de encaminarse a su resocialización (Mir Puig, 2009:87ss). Ello implica el intento de huir del paradigma de la venganza, como también el de huir de la desproporcionalidad -por ello la culpabilidad o el merecimiento del delincuente, aunque no fundamenten el castigo, al menos proporcionan su marco limitativo-.

Sobre esa base teórica se tratará de explicar la tensión a la que las tecnologías de la pantalla someten a la teoría del castigo, pues la difusión infinita del evento delictivo a través de internet y la televisión tiene el riesgo de convertir la justicia en un reality permanente. En dicho reality las exigencias de racionalidad y proporcionalidad de la pena, así como la misma presunción de inocencia, pueden verse desbordadas por las pulsiones sociales que buscan entretenimiento y que, en el peor caso, puede tomar la forma del sacrificio individual del delincuente.

\subsection{El monstruo tecnológico contra la prevención}

Desde los años 90 ha tomado protagonismo en la ciencia penal el paradigma comunicativo-preventivo de la pena (Hörnle, 2011: 22). Su idea esencial es que el castigo comunica la vigencia del derecho "a costa" del delincuente, que ha de soportar los efectos restrictivos de la pena como consecuencia de su infracción (Jakobs, 1991: 5). Al delincuente se le concibe como alguien que ha defraudado las expectativas que la sociedad proyecta sobre las personas, y no tanto como una persona a la que hay que recuperar para la "comunidad", y aún menos como alguien que ha cometido un delito del que la sociedad sea de algún modo "corresponsable".

Se renuncia, además, a la pregunta acerca de la libertad del sujeto: al delincuente no se le castiga porque fuese libre de evitar su delito, sino porque la sociedad construye una presuposición de poder individual. El "poder haber actuado de otro modo" del delincuente constituye, por tanto, una "ficción necesaria del Estado" (Jakobs, 1991: 485), un pretexto para poder castigar (Nietzsche, 1980: 95).

Por otro lado, se tiende a visualizar al delincuente como un "otro", como un "distinto", y no como alguien que podría ser “yo” (Foucault, 2001: 64ss; Garland, 2005: 191yss). La propensión mediática a calificar a delincuentes como monstruos (el "monstruo de Amstetten", el “monstruo de Cleveland", etc.) no indica sino esa tendencia. También los desarrollos teóricos del Derecho penal del enemigo, teoría por la cual habría una ley penal y unas garantías para el "ciudadano” y otras para el "enemigo" (terroristas, multi-reincidentes, delincuentes sexuales), expresan la misma idea. Así: "Quien por principio se conduce de modo desviado no ofrece garantía de un comportamiento personal; por ello, no puede ser tratado como ciudadano, sino debe ser combatido como enemigo" (Jakobs/Cancio, 2003: 55s.). La presencia de este modo de pensar en la realidad de lugares como Guantánamo indicarían que la imagen del delincuente como monstruo es mucho menos excepcional de lo que nos gustaría pensar.

94 | n 19, pp. 85-107 | doxa.comunicación 
En cualquier caso, desde estas posiciones se afirma que es el delincuente el que, con su delito, se excluye a sí mismo de la condición de "persona", al incumplir el mandato básico del derecho: "sé una persona y respeta a los demás como personas" (Hegel, 2000: 95). Si dicho incumplimiento quedase impune, la expectativa de vivir de forma segura se vería debilitada. Por ello es necesario, para evitar el caos que promueve el delito, reconstruir el clima de "seguridad" a costa de quien lo desestabilizó.

Las retransmisiones públicas en EEUU de determinadas ejecuciones de pena de muerte cumplen claramente el patrón: no basta con excluir al delincuente de la comunidad política, se le ha de excluir también de la comunidad de los vivos. Y no basta con hacerlo en silencio, sino que es necesario comunicarlo, aprovechar la oportunidad para ejercitar al ciudadano "libre" en la conciencia de que el orden social sigue vigente, de que puede seguir confiando en él, y de que debe seguir obedeciendo. El “otro" se convierte, por tanto, en condición de un "nosotros” seguro (Young, 2003: 100ss).

Varios son los argumentos en contra del paradigma preventivo del castigo. La crítica clásica es su instrumentalización del individuo, su contradicción del imperativo categórico kantiano: al castigarle en beneficio del orden social se le trata no como a un fin en sí mismo sino como a un medio (Kant, 2005: 166).

En segundo lugar, referir la pena exclusivamente a una expectativa de seguridad que se impone "a costa" del infractor lleva consigo también la tendencia a la hipertrofia de la represión penal. Si lo importante es comunicar que se puede vivir de forma segura, y si las nociones de que el delincuente es un miembro del nosotros y de que el castigo debe respetar su dignidad personal pierden su lugar en el discurso, entonces dicha seguridad, por principio siempre insuficiente, tenderá a avanzar ad infinitum a costa del infractor (Pawlik, 2012: 82).

Esta idea está ampliamente desarrollada por Foucault (2001: 80 y ss.) en su crítica a la pena preventiva, donde afirma que ésta no supone una relación de correspondencia o proporcionalidad con el crimen, sino "un desequilibrio en el corazón mismo del acto punitivo (...), una suerte de plus del lado del castigo" (80). Dicho plus lo proporciona su "carácter aterrorizador", lo cual se consigue a partir de determinados elementos. El primero es "el terror inherente al castigo", que debe "retomar en sí mismo la manifestación del crimen": debe "presentarse, representarse, actualizarse y reactualizarse en el castigo mismo" (80). El castigo se convertiría, en definitiva, en la reactualización simbólica del propio crimen. No se pretende "pasar página" y buscar un nuevo comienzo, se busca reactualizar el crimen y darle una utilidad social.

Si se observan los programas televisivos actuales dedicados a los delitos "mediáticos" se percibirá en ellos una reactualización permanente del delito. En ellos se recrea día tras día la escenografía del crimen, muy a menudo lo más morboso de la misma y lo que más efecto comunicativo tiene. El segundo elemento de la hipertrofia del castigo es que el terror debe "presentarse como insuperable e invencible", con el objetivo de conseguir la "intimidación de cualquier crimen futuro". Por esa razón no rige "la ley de medida" sino "el principio de la manifestación excesiva" del lado del castigo, "la comunicación 
de lo atroz" (81). Con ello se cumple la misión didáctica de la pena y se expande su principal mensaje: que hay que evitar comportamientos desviados, pues al sufrimiento del delito le sigue un sufrimiento mucho mayor, el del castigo.

El carácter comunicativo del castigo sería también una forma de contrarrestar el carácter expansivo del crimen: determinados delitos, particularmente el terrorismo, necesitan la televisión e internet para expandir su mensaje, razón por la cual sería necesario aprovechar dichas tecnologías de la comunicación también para difundir su castigo.

Sin embargo, los excesos del castigo penal se vuelven, finalmente, contraproducentes en relación a los efectos preventivos que supuestamente los explican. La tercera crítica contra el carácter excesivo implícito en la prevención es que la consideración del delincuente como un "monstruo" imposibilita la identificación empática en el ciudadano "normal”. Éste se representa el delito como una manifestación de la monstruosidad de aquél, y deja de percibir su linchamiento como posibilidad para sí mismo. Por otro lado, también el hecho de que la comunicación y retransmisión del castigo tenga un carácter tecnológico juega en perjuicio de la prevención: lo percibido a través de la pantalla, especialmente si tiene un carácter excesivo o espectacular, tiende a aparecer como "irreal”, como cinematográfico, como artefacto comunicativo.

Así, en la medida en que la prevención depende de que la población se identifique con el sujeto castigado ("ese podía ser yo, así que no delinquiré”), como también de que el castigo sea percibido como real ("el castigo es un sufrimiento real, así que no delinquiré"), aquélla deja de funcionar cuando el castigo se convierte en espectáculo y entretenimiento, precisamente porque sus efectos son banalizados.

La contradicción está servida: al convertir al delincuente en monstruo, su delito se tiende a percibir como producto de dicha anormalidad y no como un riesgo implícito en toda condición humana. En esa misma medida, el ciudadano "normal", aquél al que se quería ejercitar en la fidelidad al derecho, deja de recibir el estímulo psicológico del castigo. La visualización del linchamiento pasa a integrarse en el mismo cajón de la memoria colectiva donde se coloca el cine violento de Tarantino, donde se integran aquellos sucesos, quién sabe si basados en hechos reales, pero que nada tienen que ver con la pacífica realidad del ciudadano "normal".

\subsection{El linchamiento tecnológico contra la retribución y la resocialización}

En nuestro imaginario del castigo, existe también una idea de justicia con el castigado, de la necesidad de evitar excesos (Beccaria, 2008: 24). Su traducción jurídica es el principio de proporcionalidad, en el sentido de que la pena debe ajustarse a la culpabilidad del sujeto. Por otra parte, si la capacidad de culpabilidad no existe (como en el loco o en el niño) no es posible el castigo. Dicha idea de limitación se integra paradigmáticamente en la finalidad de la retribución, en tanto ella se basa en la proporcionalidad entre culpabilidad, delito y castigo (un castigo desproporcionado no retribuye sino que venga). También es reconducible, no obstante, a la prevención: un sistema penal desproporcionado y excesivamente vio- 
lento tenderá a ser percibido como ilegítimo. Con ello perdería el derecho su capacidad de generar adhesión y, con ella, su eficacia de cara a generar confianza social y prevenir delitos (Neumann, 2004: 141).

Lo que "White bear" pone de relieve es que la noción de proporcionalidad del castigo está en riesgo porque en la sociedad de la pantalla el poder de castigar se ha descentralizado, dificultando su limitación. Volviendo a la distinción anterior, es cierto que la "realidad" formal del castigo sigue en manos de profesionales de la justicia (jueces e instituciones penitenciarias), quienes hasta hace poco ejercían en nombre del Estado el monopolio del castigo. Sin embargo, su aspecto comunicativo depende cada vez menos de ellos y más de la sociedad entera, particularmente de los "gestores" del reality en que se han convertido los casos mediáticos.

Estos gestores de comunicación e información -presentadores y guionistas de programas de televisión, gestores de portales de noticias y buscadores en red, incluso fuerzas anónimas como la propia viralidad- son los que deciden cuánto tiempo pasará el delincuente en pantalla, qué imágenes y qué intimidades se difundirán del delito. Deciden en qué es necesario insistir y qué ocultar, y también en qué sentido, si en el de su culpabilidad o el de su inocencia (Montalvo, 2012: 112). Son ellos los que deciden si los casos Snowden o Assange son todavía de interés mediático, o si lo son los de Bretón y el terrorista de Boston. Ello implica que una parte hoy en día crucial del proceso penal, decisivo para el propio delincuente, está en manos de personas cuyo objetivo profesional (legítimo) es la audiencia y no el cumplimiento de la ley o la justicia.

Por otra parte, en sus orígenes el "castigo avergonzante" suponía un suplicio en la plaza pública de un pueblo, ante pocas decenas de personas a las que se impresionaba intensamente (Foucault, 1979). En la actualidad, en cambio, se ha transformado en un linchamiento más extensivo, en la nueva plaza pública planetaria, internet, donde no existen limitaciones espacio-temporales, y donde el linchamiento ajeno está disponible a golpe de click.

El caso paradigmático es el del fotógrafo Kevin Carter, ganador del Premio Pulitzer de 1994 por una fotografía de un niño sudanés hambriento a punto de ser devorado por un buitre. Ningún tribunal investigó si había cometido un delito de omisión de socorro, pero la opinión pública, en contra de toda presunción de inocencia, le condenó inmediatamente y comenzó un linchamiento a través de internet. El juicio paralelo le convirtió en el "señalado" de la audiencia. Tres meses después de ganar el premio, Carter se suicidó, sin que puedan determinarse exactamente las causas (Keller, 29.07.1994).

Con todo ello se obstaculiza, en primer lugar, todo puente posible entre el castigo y la retribución: un castigo sin limitación comunicativa no puede constituir una respuesta proporcional al daño, ni puede posibilitar en el delincuente la toma de conciencia de su delito y del carácter merecido de la consecuencia penal. Así, cuando el castigo renuncia a su racionalidad y a tener sentido para quien lo sufre, se transforma en linchamiento. Ya no supone un ejercicio "hacia dentro" de justicia y de recuperación del delincuente para la comunidad política, sino una comunicación "hacia fuera" que busca 
efectos en la conciencia colectiva, generando estabilidad social a costa del "excluido". En palabras de Luhmann: "las reconocibles consecuencias de una exclusión sirven de motivo para seguir tomando parte” (1995: 255).

La imagen mítica que proporciona el linchamiento de "White Bear" nos devuelve al mundo presente, donde se está produciendo un renacimiento de los castigos avergonzantes. En ellos se expone públicamente al delincuente portando signos o pancartas que indican el delito que cometió, como por ejemplo: "Yo robé a una niña de 9 años, no robes o esto te pasará a ti”. Son las letras-escarlata de nuestra posmodernidad, cuyo objetivo principal es comunicar la necesidad de cumplir el derecho y evitar comportamientos delictivos. Todo ello se consigue, eso sí, a costa de la posibilidad de considerar al delincuente como miembro digno del “nosotros” (Pérez Triviño, 2001; Kubiciel, 2006).

También la resocialización se ve truncada en la medida en que el castigo esté orientado a manipular pulsiones colectivas, generando adhesión a costa del delincuente, y no a justificarse ante él como una oportunidad de mejora. La resocialización, finalidad del castigo en permanente crisis desde los años 70 (Martinson, 1974), presupone que el castigo debe estar orientado a la posterior integración del delincuente en la sociedad. Ello no implica, evidentemente, que el castigo no deba ser restrictivo de sus derechos individuales: la pena, como indica su propia etimología, no deja de ser un mal (Feuerbach, 1799: 3).

Lo que añade la finalidad resocializadora a la retributiva es que el mal que se impone al delincuente no agota la totalidad del castigo, es sólo su primer momento. Existe un segundo momento en el que, dentro del marco restrictivo, el castigo es re-orientado en favor del culpable, de modo que la posibilidad de un nuevo comienzo en la sociedad aparezca más allá del cumplimiento de condena.

Sin embargo, la hipertrofia de los efectos comunicativos del castigo imposibilita una auténtica resocialización. Ésta dependería, a lo sumo, de una amnesia colectiva de la población -que habría olvidado lo que el culpable hizo-, o bien de un cambio de identidad del delincuente -que habría conseguido escapar del entorno en que todavía es "un señalado"-. En Agosto de 2013 el conocido "Violador de l'Eixample” fue liberado tras haber cumplido su condena en prisión. Sin embargo, la sociedad no ha olvidado quién es, de lo cual se han encargado ya los medios de comunicación, que están persiguiéndole permanentemente e informando de su paradero. Tampoco conseguirá escaparse fácilmente del linchamiento post-condenatorio, pues su cara y su nombre seguirán apareciendo a un golpe de click en cualquier buscador de internet. Podría posiblemente huir a otro país donde ocultar su identidad, como hizo Dolores Vázquez (Gómez, 3.6.2013), pero ello no constituirá una resocialización sino una huida.

Ello supondría una huida, serializada recientemente por Rectify (2013-), a una nueva forma de cárcel y de exclusión, construida ésta no con barrotes de hierro y guardianes carcelarios, sino más bien por redes comunicativas y Smart phones persiguiendo, apuntando y retwitteando al ex-convicto. Es, en definitiva, una continuación material del castigo. 


\section{4 .Una lectura de "White Bear"}

Afilado ya el aparato teórico de nuestra reflexión, intentaremos ahora mostrar su pertinencia a la hora de elaborar el análisis hermenéutico del texto audiovisual que es el capítulo 2.2 de Black Mirror.

La narración comienza con el despertar en una silla de Victoria Skillane, en una casa adosada típicamente inglesa. Parece recordar poco o nada sobre ella misma. A medida que sale de la habitación, baja las escaleras y explora el comedor, va descubriendo diferentes objetos. Algunos de ellos se muestran más enigmáticos, como un signo parecido a un diapasón invertido que aparece en las pantallas de la casa. Otros más directamente interpretables: el suelo repleto de pastillas y los vendajes de sus muñecas parecen hablar de uno o varios intentos de suicidio, y la fotografía enmarcada en el comedor parece mostrar junto a ella a los que deben ser su pareja y su hija.

La realidad se presenta al comienzo como un conjunto de signos a interpretar. Por eso el espectador se identifica fácilmente con ella, produciéndose lo que Murray Smith ha descrito como alineamiento entre el personaje y el espectador, como "el modo en que una película nos da acceso a las acciones, pensamientos y sentimientos de los personajes" (1995: 6). Ello se produce no sólo porque ella esté desvalida, sino porque se encuentra huérfana de significado y busca entender quién es y qué es lo que está sucediendo.

Avanza la trama y aparecen sucesivos elementos antagonistas que incrementan la amenaza y el malestar tanto de la protagonista como del espectador alineado. Al salir a la calle, aparentemente desierta, Victoria se da cuenta de que hay gente que la filma con su móvil desde lejos o desde las ventanas de las otras casas. Intenta hablar con ellos para que le ayuden a aclarar la situación, pero se muestran elusivos y huyen de ella antes de que pueda acercárseles. Empieza entonces el proceso de filiación (allegiance) entre la protagonista y el espectador, descrito como "el modo en que una película intenta manipular nuestras simpatías hacia o contra los diversos personajes en el mundo de ficción” (Smith, 1995: 6).

A partir de ese momento, el espectador se identifica plenamente con Victoria, percibida como la víctima de la situación. Poco después, esta identificación se irá reforzando con la aparición de nuevas amenazas. De repente aparece un Rolls Royce con un encapuchado que empieza a disparar contra ella de modo gratuito. Victoria huye. Es perseguida hasta una gasolinera donde encuentra a otros dos supervivientes todavía humanos, no alienados por las pantallas de sus móviles, con los que se refugia en la caseta de la gasolinera de los disparos del encapuchado. El chico muere de un disparo, pero ellas dos consiguen escapar. Siguen persiguiéndolas el encapuchado anterior más otros dos personajes armados y enmascarados, como también una horda de ensimismados en pantallas de móvil y tablets.

La chica de la gasolinera pone mínimamente a Victoria al corriente de la situación. Le explica que la señal del diapasón que ha visto en las pantallas de casa es emitida en todas las pantallas de la región desde una central. Producto de ello, la gente queda mesmerizada. La humanidad libre queda reducida a unos pocos supervivientes como ellas y a un grupo de psicó- 
patas o sociópatas que han aprovechado la situación para poner en práctica su comportamiento abiertamente criminal. La explicación se hace razonable para el espectador. Parece que el género en el que nos movemos es el del terror apocalíptico, lo cual favorece de nuevo el proceso de alineamiento.

En esa huida desesperada reciben la ayuda de un hombre que conduce una furgoneta. Las libra del inminente ataque de los dos asesinos enmascarados, pero no quiere llevarlas donde ellas piden ir: la central emisora de la señal. Les dice que las lleva al bosque, a un lugar seguro, mientras que Victoria, en un estado alucinado, parece ir reconociendo algunas de las frases y lugares que se van sucediendo. Llegan a su destino y su salvador muestra su verdadera identidad. Es otro de esos psicópatas, aunque vaya descubierto. Las conduce a punta de escopeta a un paraje donde hay numerosos cadáveres de hombres y mujeres que han sido torturados hasta la muerte. Sus cuerpos se exhiben colgados o crucificados en los árboles. Parece que aquel hombre pretende hacer lo mismo con ellas, ante la mirada de un número creciente de hombres, mujeres y niños que parecen hipnotizados en sus propias grabaciones de la escena.

Aprovechando un despiste del captor, la chica de la gasolinera consigue escapar, pero Victoria queda en manos de él. Se dispone a torturarla, pero la chica de la gasolinera la salva in extremis robándole el arma al torturador cuando éste se disponía a agredirla con una taladradora teniéndola ya atada a un árbol. Así, se zafan del cautiverio y roban la furgoneta cuando estaban llegando los otros dos agresores enmascarados. Conducen hacia la central emisora de la señal. Quieren destruirla para que la gente deje de comportarse como si fuesen zombis alienados por la pantalla.

Llegan ya de noche, fuerzan la valla de seguridad y entran en uno de los edificios, con una gran lata de gasolina, dispuestas a incendiar y destruir la maquinaria de emisión de la señal del diapasón electrónico. Cuando se disponen a hacerlo, irrumpen en escena los perseguidores y se inicia un forcejeo con ellos, producto del cual Victoria dispara la escopeta contra uno, saliendo del cañón confeti, ante la estupefacción del espectador ansioso por la situación de peligro, en la que se identifica claramente con Victoria.

En ese preciso momento se revela cómo en "White Bear” el narcisismo televisivo no es el único tipo de metaficción que se utiliza para hacer consciente al espectador. Hay en juego otra metaficción clamorosa. Entra en escena precisamente cuando se dispara el confeti y, acto seguido, lo que parecía ser una central de emisión semi-abandonada se convierte en el escenario de un espectáculo. Con ello, el espectador se da cuenta de que lo que ha estado viendo no era más que parte de una especie de reality, donde Victoria era la protagonista sin saberlo. En ese preciso instante, el espectador accede tanto a la conciencia de la manipulación a la que estaba siendo sometido por el artefacto narrativo que veía en la pantalla (ahora se puede reconocer a sí mismo en la posición de los alienados en las pantallas de los móviles), como a la verdad y reinterpretación de la misma narración (lo que el espectador ha estado viendo es un reality show, no una película de terror). 
Producido este supuesto giro de la trama, en el que del género de terror se pasa a un reality diegético, se empiezan a encadenar los datos que permiten la reinterpretación íntegra de lo que ha sucedido hasta el momento. El proceso se alargará hasta los títulos de crédito finales, entre los que se intercalarán imágenes que permitirán al espectador entender con mayor precisión qué es lo que ha estado sucediendo realmente. Sin ánimo de alargarnos en este particular, diremos que Victoria es una convicta por el asesinato a sangre fría de una niña de color (la chica de la foto que ella creía que era su hija) a la que ella y su pareja habían previamente raptado.

Su novio se suicidó en la cárcel para evitar el castigo. Sin embargo, el sistema ideó un sistema penitenciario específico para evitar que Victoria se suicidase y eludiera el peso de la ley: un parque temático de la justicia que es a la vez una instalación de entretenimiento, donde participan familias enteras que filman lo que allí sucede con sus móviles (previos supuestos zombis de la señal del diapasón), y una administración de castigos supuestamente ejemplarizantes. Cada día se despierta en la misma silla y vive la misma angustia participando en una ficticia huida desesperada y alucinante que ella vive como real. Se encargan de que así sea el conjunto de actores que regentan la instalación y un instrumento electrónico que le borra la memoria cada día. Así, la vida de Victoria se convierte en una especie de eterno retorno de la misma angustia, sin fin, y sin otra finalidad que la venganza de la sociedad con respecto a su acto criminal.

Dicho esto, vayamos a la "segunda navegación” sobre el texto, que según García-Noblejas consiste en un momento personal del espectador que implica dos cosas: "la comprensión intelectual -técnica- de un texto" (que hemos intentado ilustrar hasta ahora), y la aplicación vital del "sentido de ese texto por parte de la persona” (2004: 76-77). Se trata de un trabajo de interpretación que no es plenamente extrínseco con respecto al texto audiovisual comentado, ya que tanto la metaficción comentada como el alineamiento y la filiación del espectador con la criminal impelen a realizarla. Así, teniendo en cuenta el aparato teórico anteriormente mencionado con respecto a la teoría del castigo, intentaremos realizar esta segunda navegación en la que se intenta descubrir qué desvela el capítulo comentado sobre nuestro mundo presente.

Creemos que lo que el visionado de "White Bear" permite es precisamente la reflexión acerca de la transformación del imaginario del castigo a través de las nuevas tecnologías. En el capítulo se cumplen claramente gran parte de los patrones del imaginario preventivo esbozado, así como sus peligros.

Para empezar, el castigo de la protagonista tiene la forma de reality penitenciario, donde familias enteras participan como espectadoras curiosas que graban su linchamiento mediático, dándole circulación viral a través de sus tablets y sus smartphones. La ejecución de dicho castigo, además, reside en manos de comunicadores: el justiciero es un presentador de televisión, especialista en despertar las pulsiones de la masa de consumidores de espectáculo, de puro entretenimiento; y los guardianes del parque de justicia son actores profesionales. El castigo es pura comunicación. 
Por otro lado, también se aprecia en "White bear" la tendencia a la hipertrofia del castigo preventivo. El terror y la reactualización del crimen son intrínsecos al linchamiento: al final de cada uno de los días que componen el reality, Victoria es obligada a presenciar la grabación del delito que ella misma realizó con su móvil. La escenografía del delito y del crimen son el mismo bosque, y la señal que parece alienar a los espectadores es un símbolo que ella tiene tatuado en su cuerpo.

Sin embargo, el propio imaginario del castigo, al exagerar la imagen del linchamiento del monstruo, se vuelve contraproducente respecto a todos sus posibles fines. Respecto a la prevención, porque los espectadores dejan de ver a la protagonista como una persona, y pasan a excluirla del “nosotros” y a ver en ella un “mero cuerpo" (Foucault, 1979: 32; Luhmann, 1995: 262).

De ello se encarga el propio justiciero, que prohíbe a los espectadores hablar con ella, rompiendo la posibilidad de comunicación y reconocimiento personal. Les alienta, en cambio, a fotografiar y grabar la escena, esto es, a convertirla en un objeto de la comunicación, a instrumentalizarla, a divulgarla para incrementar la vergüenza de la rea-víctima. En la medida en que se distancia en tal medida al "monstruo" del espectador "normal", este último pasa a ver la escena como un macabro teatro del entretenimiento, perdiendo por ello el castigo su capacidad motivadora y preventiva. El espectador deja de sentirse aludido como congénere del criminal, puesto que el castigado, a sus ojos, deja de serlo: es el súmmum de la anormalidad, el monstruo.

Más evidente aún es la renuncia a la posibilidad de la retribución. En la medida en que a Victoria se le induce diariamente una amnesia no es capaz de recordar su delito, por lo que su sufrimiento, además de desmedido, se convierte en un "absurdo" que no puede ser comprendido como merecido, ni motivar un cambio interior en ella.

Como especie de linchamiento, su castigo no sólo funciona en contra de la proporcionalidad, sino también de la resocialización. A quien es expuesto en esa medida al escarnio público multitudinario sólo le queda la huida, la auto-exclusión. Y probablemente no sólo de la sociedad condenadora, sino en ocasiones incluso del mundo de los vivos. Victoria suplica, al final del capítulo, que la maten -“Kill me, please", repite- precisamente porque no adivina posibilidad alguna de un nuevo comienzo más allá del castigo. Ello remite al riesgo real, potenciado por las nuevas tecnologías, que suponen fenómenos actuales como los juicios mediáticos paralelos, capaces de distorsionar el proceso judicial y sus garantías, convirtiendo el reguero de publicaciones en una magnificación de la pena a través del limbo de internet.

\section{Conclusión}

En el recorrido teórico y hermenéutico realizado creemos haber evidenciado que el capítulo "White Bear", perteneciente a la mini-serie británica Black Mirror, constituye un buen ejemplo de lo que hemos denominado pensamiento pop. En pri- 
mer lugar, porque permite, a través de un producto de entretenimiento, una clara reflexión crítica con respecto a nuestro mundo actual, donde las nuevas tecnologías incrementan día a día su presencia e impacto psicológico y sociológico. En segundo lugar, porque utiliza algunos de los mecanismos formales y retóricos, como la metaficción, el alineamiento y la filiación (allegiance), que permiten al guionista plantearle al espectador determinados problemas y fricciones del mundo en el que vive.

Por otra parte, el capítulo permite sacar conclusiones respecto a los peligros de los nuevos media en el imaginario de lo que consideramos un castigo justo. En él se percibe de qué modo la confusión de los espacios del castigo y del espectáculo puede producir una grave distorsión en el sistema penal. En primer lugar, por el riesgo de convertir al acusado en un monstruo y excluirle del espacio público del "nosotros". En segundo lugar, por el riesgo de convertir el castigo en un linchamiento mediático desproporcionado, incapaz de inspirar confianza social y prevenir delitos, así como de resocializar al propio delincuente.

Queda así demostrado, con un posible caso, que la condición de entretenido no descarta a un producto audiovisual para generar pensamiento crítico con respecto a una sociedad y a una cultura. Puede ser portador de una posibilidad de pensamiento pop, que nunca es algo mecánico, sino una oportunidad de reflexión propia del espectador, que puede ser ayudado por el visionado experto y/o por el visionado compartido del producto audiovisual.

Probablemente sea verdad que "ahora es la televisión la que toma elementos de la posmodernidad (...) y los manipula en aras del consumo" (Wallace, 2008: 83), pero eso sería menos problemático en tanto, como hemos visto, tecnología, consumo y entretenimiento podrían no ser heterogéneos al pensamiento crítico.

\section{Referencias bibliográficas}

Appadurai, A. (2001): La modernidad desbordada. Buenos Aires: FCE.

Balandier, G. (1994): El poder en escenas. Barcelona: Paidós.

Balandier, G. (1996): El desorden. La teoría del caos y las ciencias sociales. Elogio de la fecundidad del movimiento. Barcelona: Gedisa.

Barraycoa, J. (2003): Sobre el poder en la modernidad y en la posmodernidad. Barcelona: Scire.

Baudrillard, J. (1978): Cultura y simulacro. Barcelona: Kairós.

Beccaria, C. (2008): De los delitos y las penas. Madrid: Tecnos.

Bellón, T. (2012): “Nuevos modelos narrativos. Ficción televisiva y transmediación”, Revista Comunicación, vol. 10, n. 1, pp. 17-31. 
Boggs, C. y Pollard, T. (2001): "Postmodern Cinema and Hollywood Culture in an Age of Corporate Colonization", Democracy \& Nature, vol. 7, n. 1, pp. 159-181.

Boudieu, P.(1997): Sobre la televisión. Barcelona: Anagrama.

Calabrese, O. (1989): La era neobarroca. Madrid: Cátedra.

Carr, N. (2013): Superficiales. ¿Qué está haciendo internet con nuestras mentes? Madrid: Taurus.

Carretero, A. E. (2006): “La persistencia del mito y de lo imaginario en la cultura contemporánea”, Política y Sociedad, vol. 43, n. 2, pp. 107-126.

Cascajosa Virino, C. (2006): "No es televisión, es HBO: La búsqueda de la diferenciacomo indicador de calidad en los dramas del canal HBO”, ZER, n. 21, pp. 23-33.

Castoriadis, C. (1987): The Imaginary Institution of Society. Cambridge: Polity Press.

Castoriadis, C. (2005): Los dominios del hombre. Barcelona: Gedisa.

Debord, G. (2000): La sociedad del espectáculo. Valencia: Pre-Textos.

Durand, G. (2004): Las estructuras antropológicas del imaginario. Madrid: FCE.

Feuerbach, L. A. (1799): Revision der Grundsätze und Grundbegriffe des positivenpeinlichenRechts. Teil I. Erfurt.

Feuerbach, L. A. (1986): Lehrbuch des gemeinen in Deutschland geltendenPeinlichenRechts. ScientieVerlagAalen (original, 1801).

Foucault, M. (1979): Vigilar y castigar. Nacimiento de la prisión. Madrid: Siglo XXI.

Foucault, M. (2001): Los anormales. Madrid: Akal.

García Martínez, A. N. (2009): “El espejo roto: la metaficción en la series anglosajonas”, Revista Latina de Comunicación Social, n. 64, pp. 654-667.

García-Noblejas, J. J. (2004): “Identidad personal y mundos cinematográficos distópicos”, Comunicación y Sociedad, vol. XVII, n. 2, pp. 73-87.

Garland, D. (2005): La cultura del control. Barcelona: Gedisa.

Gómez, L. (2013): “No hay perdón para Dolores Vázquez”, El País (3 de Junio de 2013), http://politica.elpais.com/politica/2013/06/02/actualidad/1370190300_472322.html [Consultado el 23/12/2013].

Gómez Urzáiz, B. (2013): "Si recargar un iPhone nos quitase 10 minutos de vida, lo haríamos" (Entrevista a Charlie Brooker), El País (4 de Diciembre de 2013), http://elpais.com/elpais/2013/12/04/icon/1386194137_786585.html [Consultado el 20/12/2013].

Hegel, G. W. F. (2000): Grundlinien der Philosophie des Rechts. Frankfurt am Main: Suhrkamp. 
Hörnle, T. (2011): “GegenwärtigeStrafbegründungstheorien: Die herkömmiche deutsche Diskussion”, en von Hirsch, A., Neumann, U. y Seelmann, Kurt (eds.): Strafe Warum?. Baden-Baden: Nomos, pp. 11-30.

Imbert, G. (2008): El transformismo televisivo. Madrid: Cátedra.

Imbert, G. (2010): Cine e imaginarios sociales. Madrid: Cátedra.

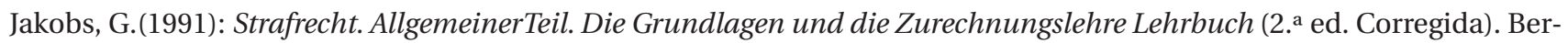
lin/New York: Walter de Gruyter.

Jakobs, G. (2006): La pena estatal: significado y finalidad. Madrid: Thomson-Civitas.

Jakobs, G. y Meliá, C. (2003): Derecho penal del enemigo. Madrid: Thomson-Civitas.

Kant, I. (2005): La metafísica de las costumbres. Madrid: Tecnos.

Keller, B. (1994): “Kevin Carter, a Pulitzer Winner For Sudan Photo, Is Dead at 33”, New York Times (29 de Julio de 1994), http://www.nytimes.com/1994/07/29/world/kevin-carter-a-pulitzer-winner-for-sudan-photo-is-dead-at-33.html [Consultado el 10/1/2014].

Kibiciel, M. (2006): “Shame Sanctions. Ehrenstrafenim Lichte der Straftheorie”, ZStW118, pp. 45-75.

Lipovetsky, G. y Serroy, J. (2009): La pantalla global. Cultura mediática y cine en la era hipermoderna. Barcelona: Anagrama.

Luhmann, N. (1993): Das Recht der Gesselschaft. Frankfurt am Main: Suhrkamp.

Luhmann, N. (1995): Soziologische Aufklärung 6. Die Soziologie und der Mensch. Darmstadt: WestdeutscherVerlag.

Lyotard, J. F. (1987): La condición posmoderna. Madrid: Cátedra.

Maffesoli, M. (2003): “El imaginario social”, Revista Anthropos. Huellas del conocimiento, n. 198, pp. 149-153.

Maffesoli, M. (2004): El tiempo de las tribus. El ocaso del individualismo en las sociedades posmodernas. México D.F.: FCE.

McLuhan, M. (2009): Comprender los medios de comunicación: las extensiones del ser humano. Barcelona: Paidós.

Mir Puig, S. (2009): Derecho penal. Parte general. Barcelona: Reppetor.

Montalvo Abiol, J. C. (2012): “Los juicios paralelos en el proceso penal: ¿Anomalía o mal necesario?”, Universitas. Revista de Filosofía, Derecho y Política, n. 16, pp. 105-125.

Neumann, U. (2004): "La interpretación ontológica, funcional y ético-social del principio jurídico-penal de culpabilidad”, Revista de Derecho penal y Criminología, 2. á Época, n. 13, pp. 135-150.

Nietzsche, F. (1980): SämtlicheWerke. KritischeStudienausgabe. Band 6. Berlin/New York: Walter de Gruyter.

Olson Scott, R. (1987): “Meta-television: Popular Postmodernism”, Critical Studies in Mass Communications, n. 4, pp. 284300. 
Pawlik, M. (2012): Das Unrecht des Bürgers: Grundlinien der AllgemeinenVerbrechenslehre. Tübingen: Mohr Siebeck.

Pérez Bowie, J. A. (2005): “El cine en, desde y sobre el cine: mataficción, reflexividad e intertextualidad en la pantalla”, Revista Anthropos. Huellas del conocimiento, n. 208, pp. 122-137.

Pérez Gómez, M. A. (ed.) (2011): Previouslyon: estudios interdisciplinarios sobre la ficción televisiva en la Tercera Edad de Oro de la Televisión. Sevilla: Facultad de Comunicación de la Universidad de Sevilla.

Pérez Triviño, J. L. (2001): “El renacimiento de los castigos avergonzantes”, Isonomía: Revista de Teoría y Filosofía del Derecho, n. 15, pp. 193-207.

Postman, N. (1998): Tecnópolis: la rendición de la cultura a la tecnología. Barcelona: Galaxia Gutenberg.

Postman, N. (2012): Divertirse hasta morir. Barcelona: La Tempestad.

Rheingold, H. (2012): Net Smart. How to Thrive Online. Cambridge (MA): MIT Press.

Ritzer, G. (2000): El encanto de un mundo desencantado: revolución en los medios de consumo. Barcelona: Ariel.

Sartori, G. (1998): Homo videns, la sociedad teledirigida. Madrid: Taurus.

Schünemann, B. (2003): “Zumgegenwärtigen Stand der Lehre von der Strafrechtsschuld”, en: Dölling, D. (ed.), Jus humanum: Grundlagen des Rechts und Strafrecht. Festschrift für Ernst-Joachim Lampe zum 70.Geburtstag. Drucker \& Humbolt: Berlin, pp. 537-560.

Sepinwall, A. (2012): The Revolution was televised. The Cops, Crooks, Slingers and Slayers Who Changed TV Drama Forever. Londres: auto-publicación.

Smith, M. (1995): Engaging characters: fiction, emotion, and the cinema. Oxford: Clarendon Press.

Taylor, C. (2006a): Fuentes del yo. La construcción de la identidad moderna. Barcelona: Paidós.

Taylor, C. (2006b): Imaginarios sociales modernos. Barcelona: Paidós.

Teubner, G. (2002): “El derecho como sujeto epistémico: hacia una epistemología constructivista del Derecho”, Doxa, n. 25, pp. 533-573.

Tous, A. (2009): "Paleotelevisión, neotelevisión y metatelevisión en las series dramáticas estadounidenses", Comunicar, vol. XVII, n. 33, pp. 175-183.

Thompson, C. (2012): Smarter Than You Think: How Technology is Changing Our Minds for the Better. New York: The Penguin Press.

Wallace, D. F. (2008): “E unibuspluram”, en Wallace, D. F: Algo supuestamente divertido que nunca volveré a hacer. Barcelona: Mondadori, pp. 33-100. 
Waugh, P. (1984): Metafiction. The Theory and Practice of Self-Conscious Fiction. London \& New York: Routledge.

Young, J. (2003): La sociedad "excluyente”: Exclusión social, delito y diferencia en la Modernidad tardía. Madrid: Marcial Pons. 